
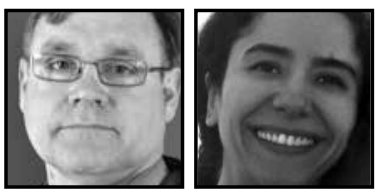

\title{
Science Education for Social Justice Using the Knowledge-Building Communities Model
}

\author{
Richard Reeve and Azza Sharkawy, Queen's University
}

\begin{abstract}
In this article, we explore the connections to, and potential contributions of, the knowledge-building communities (KBC) model to science education for social justice. We examine the principles and design features that underpin the $\mathrm{KBC}$ model and reflect on the ways in which they are consistent with, and support some of, the important dimensions of science education for social justice, including: 1) building on students' ideas and interests; 2) encouraging and valuing the inclusion of diverse perspectives; 3) collaborative participation and community; and 4) fostering engagement with the outside world.
\end{abstract}

\section{Science Education for Social Justice}

\footnotetext{
$\mathrm{n}$ broad terms, science education focused on social justice embraces two goals. First, it is concerned with making science education more accessible to all students, especially those belonging to groups traditionally marginalized from science education (e.g., females, Aboriginals). Second, it aims to equip student with the knowledge, skills and, most importantly, a commitment to taking action to create a more socially just and environmentally sound world (Barton, 2003; Bencze \& Alsop, 2009; Hodson, 1998, 2003). Science education for social justice is informed by the progressive education movement (Hein, 2012), most notably associated with the writings of John Dewey. The progressive educational approach that Dewey developed requires, in addition to adopting his active child-centered pedagogy, that one embrace a socio-political agenda as the moral aim of education (Hein, 2012). Subsequently, in
} 
the hands of a series of scientist/educators, active ways of engaging children in science have been explored by people including David Hawkins at the Hawkins Centers for Learning (Hawkins, 1974), Frank Oppenheimer at the Exploratorium (Cole, 2009), and Jerrod Zacharias at the Education Development Center (Goldstein, 1992). In all of these cases a connection was made between the importance of practicing a pedagogy that increased students' science knowledge and promoting active student participation in the service of democracy and social justice. In Zacharias' case it has been said,

His faith in the power of science to improve society, not through its technical accomplishments but through the potential of science education to help people think clearly and make informed judgments, matches Dewey's repeated emphasis on the need for education that promotes thinking and inquiry in support of social goals of a democratic society. (Hein, 2012, p. 172)

\section{Knowledge-Building Communities (KBC) Model}

The knowledge-building communities (KBC) model is an educational approach that promotes democratic ideals by requiring all participants to engage as a community in the production of knowledge that is continually improved for the benefit of the community (Scardamalia \& Bereieter, 2003; Scardamalia, 2002). There are 12 principles that underpin the KBC model, and in point form, include: 1) real ideas, authentic problems; 2) improvable ideas; 3) idea diversity; 4) rise above; 5) epistemic agency; 6) community knowledge; collective responsibility; 7) democratizing knowledge; 8) symmetric knowledge advancement; 9) pervasive knowledge building; 10) constructive use of authoritative sources; 11) knowledge-building discourse; and 12) embedded and transformative assessment. For a thorough presentation of these principles, please see Scardamalia, 2002; and Scardamalia and Bereiter, 2006.

In contrast to other constructivist pedagogies (e.g., project-based learning), the $\mathrm{KBC}$ model requires that students set personal and group goals, acquire and critique resources, monitor ongoing growth, and modify their strategies in light of the progress they are making both individually and as a group (Hmelo-Silver \& Barrow, 2008). Students are encouraged to identify problems of interest, conduct research on these problems, and engage in community discourse with awareness that collective understanding, rather than individual learning and performance, is the goal (Caswell \& Bielaczyc, 2001).

The KBC model involves the use of the Knowledge Forum ${ }^{\circledast}(\mathrm{KF})$ software environment to facilitate student sharing of questions, theories, and information (Scardamalia 
\& Bereiter, 1996, 2003, 2006). As a collaborative computer environment involving a communal database, KF provides support for community knowledge building that allows individuals to read, reflect on, and respond to their own ideas and the ideas of others. The database contains tools that allow students to further build upon other students' ideas, raise issues for further exploration and, where appropriate, rise above these ideas by subsuming them into a new note structure. As such, KF provides an online environment for groups to carry on collaborative knowledge work among themselves and with others outside of their local community.

\section{Organization of Article}

Our review of the $\mathrm{KBC}$ model will focus on the relationship among the $\mathrm{KBC}$ principles, common design features and the manner in which the model supports elementary science education for social justice. Below we reflect on the ways in which the KBC principles and design features are consistent with and support the following dimensions of science education for social justice: 1) building on students' ideas and interests; 2) encouraging and valuing the inclusion of diverse perspectives; 3 ) collaborative participation and community; and 4) fostering engagement with the outside world. After reviewing the social justice connections to the $\mathrm{KBC}$ model, we illustrate these points by briefly presenting two contrasting classroom implementations of the $\mathrm{KBC}$ model. The first example is taken from the grade 5/6 teaching experiences of the first author and illustrates both the common design features of a KBC classroom and the inclusive and expansive nature of a KBC approach to science education. The second example is from a different grade $5 / 6$ class (with whom the authors conducted research) that was part of an international network focused on advancing student understanding of climate change.

\section{Building on Students' Ideas and Interests}

Traditionally, science education is based on predetermined learning objectives that may have little or nothing to do with students' interests or concerns. As such, science education is often perceived by students as being overly abstract and irrelevant to their lives (Hodson, 1998). This is particularly the case for students belonging to groups that have historically been marginalized from science education (e.g., females, Aboriginals). Often, science concepts are extracted from official curriculum documents and presented in contexts that are foreign to these students (Aikenhead, 2006), resulting in students distancing themselves from science, or at best, engaging superficially with science lessons. As Roth and Barton (2004) note: 
...Students from all different kinds of backgrounds arrive at school class and are subject to a homogeneous body of knowledge upon which they are tested at the culmination of the school year. Science is defined not by how one manages, alone or collectively, to use or produce science by way of this knowledge at home or at school, in response to a need or concern or practically toward their own or their community's future. Rather, success takes the form of a predetermined response to a cooked-up problem, an abstract set of ideals... (p. 8)

Central importance of student ideas (real ideas, authentic problems). “Knowledge problems arise from efforts to understand the world. Ideas produced or appropriated are as real as things touched and felt. Problems are ones that learners really care about-usually very different from textbook problems and puzzles" (Scardamalia, 2002, p. 76). This KBC principle recognizes students' ideas and problems of understanding as the starting points for student knowledge building. This principle supports the development of science curricula that build on students' funds of knowledge (Moll, 1992) and is personally and culturally relevant to students. This is consistent with culturally responsive curriculum that emphasizes the need to take into account the knowledge, beliefs, values, aspirations, and personal experiences of individual students (Hodson, 1998).

All student ideas are improvable (improvable Ideas). In the KBC model, students are encouraged to actively engage in what they are doing and to view all ideas as improvable. "All ideas are treated as improvable. Participants work continuously to improve the quality, coherence, and utility of ideas. For such work to prosper, the culture must be one of psychological safety, so that people feel safe in taking risks" (Scardamalia, 2002, p. 76). The progressive improvement of society is modeled in the way ideas are raised, discussed, and moved forward by a KBC.

\section{Students have agency over their ideas and, in turn, the direction of the curriculum} (epistemic agency). Empirical research using the KBC model has demonstrated that students as young as kindergarten can exercise control over their ideas when given the opportunity (Tarchi et al., 2012). The KBC model encourages students to take an active role in designing their learning experiences by centering discussion on their ideas and concerns. Students develop the skills and dispositions necessary to "take over highlevel knowledge work (generating ideas and plans, evaluating results, etc...) usually reserved for teachers" (Scardamalia, 2002, p. 77). The KBC model teaches students to become self-directed learners who can take initiative. Contributing to a socially and environmentally just society requires individuals who can take initiative, create plans for taking action on important social/scientific issues, monitor their progress, 
and evaluate their efforts. Becoming agents of social change requires active rather than passive citizens.

\section{Encouraging and Valuing the Inclusion of Diverse Perspectives}

Often the goal in science classrooms is for students to learn the correct theory or scientific concept. A deliberate effort to introduce diverse perspectives is often lacking and the potential and importance of understanding and comparing diverse perspectives is overlooked. The following three principles of the $\mathrm{KBC}$ model promote the goal of encouraging and valuing the inclusion of diverse perspectives: Idea Diversity, Democratizing Knowledge, and Constructive Uses of Authoritative Sources.

Respecting the diversity of student ideas (idea diversity). Underpinning this principle is an authentic (rather than token) recognition of the importance of diverse ideas or perspectives. As noted by Scardamalia (2002), "To understand an idea is to understand the ideas that surround it, including those that stand in contrast to it. Idea diversity creates a rich environment for ideas to evolve into new and more refined forms" (p. 76). This principle is consistent with multicultural education frameworks that emphasize the importance of helping students appreciate and respect multiple perspectives and providing a safe space for students to express their diverse ideas and worldviews (e.g., Banks, 1996).

\section{All members of the community have a democratic right to participate} (democratizing knowledge). This principle states that,

All participants are considered legitimate contributors to the shared goals of the community. All take pride in the knowledge advances achieved by the group. The group's diversity and divisions do not translate into hierarchies of "knowledge haves and have-nots" or "innovators and non-innovators." (Scardamalia, 2002, p. 78)

This principle emphasizes that all students, not just those typically recognized as academically strong, are empowered to contribute to and feel pride in progress made to the goals of the classroom community. The focus of this principle on the collective/ group rather than the individual is consistent with culturally responsive pedagogy (Nieto, 2010).

Students take a critical stance on resources (constructive uses of authoritative sources). "To know a discipline is to be in touch with the present state and growing edge of knowledge in the field. This requires respect and understanding of authoritative sources, combined with a critical stance toward them" (Scardamalia, 2002, p. 78). 
This principle highlights the importance of students learning to constructively critique the sources they consult to support their knowledge-building efforts. This is important, from a science education for social justice perspective, because science resources are imperfect. Sometimes, for example, science resources can misrepresent the nature of science and convey an image of science as a set of absolute facts. Helping students to constructively use authoritative sources also contributes to the diversity of ideas that are introduced into the KBC classroom.

\section{Collaborative Participation and Community}

Although collaboration is recognized as being an important skill that students in science education should develop, rarely is it integrated deeply into the culture and fabric of a classroom. Collaborative participation and a strong sense of community are important features of an inclusive classroom (Nieto, 2010). There are several principles underpinning the $\mathrm{KBC}$ model that promote collaborative participation and community: Community Knowledge, Collective Responsibility, Embedded and Transformative Assessment, Rise Above, and Knowledge-Building Discourse.

Responsibility to participate (community knowledge, collective responsibility). This KBC principle emphasizes collective responsibility for the generation of knowledge that is of value to the local and broader community (Scardamalia, 2002).

Contributions to shared, top-level goals of the organization are prized and rewarded as much as individual achievements. Beyond the right to participation in a knowledge building community, individual members have a responsibility to participate in ways that advance community knowledge. As a community, any effort to build knowledge or take action needs to be for the benefit of the community. Team members produce ideas of value to others and share responsibility for the overall advancement of knowledge in the community. (p. 77)

Many cultures value collaboration and find it more productive to learn in a collaborative community. Thus, an emphasis on the community rather than individual is consistent with culturally relevant pedagogy (Nieto, 2010).

\section{Ongoing assessment supports progress (embedded and transformative} assessment). "Assessment is part of the effort to advance knowledge-it is used to identify problems as the work proceeds and is embedded in the day-to-day workings of the organization. The community engages in its own internal assessment" (Scardamalia, 2002 , p. 79). The KF software environment provides the means for ongoing simultaneous 
embedded assessment by virtue of all members being able to communicate about each other's ideas, and in that moment provide reflection on the meaning and importance to themselves and to the community.

\section{Rise above leads to progress (rise above).}

Working toward more inclusive principles and higher-level formulations of problems. It means learning to work with diversity, complexity and messiness, and out of that achieve new syntheses. By moving to higher planes of understanding, knowledgebuilders transcend trivialities and oversimplifications and move beyond current best practices. (p. 77)

Although this KBC principle is cast in terms of movement to "higher planes of understanding" the underlying operative concern is for the questions, "Are we getting somewhere significant to us?" and "If so, where is that taking us and how do we define it?" Both of these questions are reflective and assessment-oriented. They lead the group that undertakes the creation of a rise-above note in the KF environment to engage in significant reflection about the state of their current and past knowledge work, and to set new goals for moving forward with their knowledge building.

\section{Students engage in progressive inclusive dialogue (knowledge-building} discourse). Knowledge-building discourse is progressive inclusive dialogue that allows all students to have a voice into the conversation. That the Knowledge Forum software environment affords the classroom an online space to discuss the knowledge being developed is understood. Yet, there is also a need that develops in each class that requires the development of a way to talk about the knowledge building off of the computers. Face-to-face discourse that mirrors the transformative discourse supported by the KF environment is essential. Overall,

The discourse of Knowledge Building Communities results in more than the sharing of knowledge; the knowledge itself is refined and transformed through the discursive practices of the community (through) practices that have the advancement of knowledge as their explicit goal. (p. 78)

Classroom discourse in a $\mathrm{KBC}$, both in the collaborative online environment and in face-to-face conversation, is oriented toward open acceptance of and working with the ideas of others. Discourse is rendered more as dialogue between collaborators interested in the development of knowledge of value to the local community. Critiques of the ideas are welcome as they lead to improvements and benefit the overall 
well-being of the community. From a social justice point of view, students need to be able to learn how to "critique" not only their own, but also other people's ideas. Most importantly, students need to learn to recognize the fact that multiple perspectives on issues/questions/problems exist and then learn how to successfully work with these multiple perspectives. What we want is for students to eventually learn how to engage in this evaluation of perspectives and learn that the degree to which an idea/theory/ perspective is productive is dependent on the context. As noted by Hodson (1998), it is important to help students develop the

second order understanding that includes: a) recognizing that alternative conceptions and explanations exist (and alternative methods too); b) appreciating that the appropriateness and usefulness of knowledge are determined by context; c) knowing what knowledge to access and how to use it in a variety of problem situations and social contexts. (p. 127)

\section{Fostering Engagement With the Outside World}

Socio-political concerns associated with social justice education are broad and expansive, encompassing a general concern for the promotion of democracy and the improvement of life in general for all those involved, but mostly for those least well-off (Hein, 2012). Dewey (1916) defines society as "one by its very nature. The qualities which accompany this unity, praiseworthy community of purpose and welfare, loyalty to public ends, mutuality of sympathy, are emphasized" (p. 82). Education for social justice requires connections be made to the general concerns of society beyond the classroom walls. A current example of this approach to activist education is the STEPWISE program (Bencze \& Alsop, 2009).

STEPWISE orients most learning outcomes in science and technology education towards 'WISE Activism,' which is/are action(s) people might take to overcome problems for the 'well-being of individuals, societies and environments' (WISE) associated with fields of science and technology and their products and services. (p. 72)

The degree to which science education for social justice is instantiated through the use of the KBC model varies depending on the degree to which the following $K B C$ principles are implemented with connection to, and interaction with, the outside world: Real Ideas, Authentic Problems, Pervasive Knowledge Building and Symmetric Knowledge Advancement. 
Authentic problem in the world at large (real ideas, authentic problems). Although we highlighted this principle as important in the section building on students' ideas and interests, it is also relevant in the context of connecting students to authentic societal issues outside the classroom walls. When classroom communities take on societal problems as the focus of their knowledge-building work, they transform their efforts from being of benefit to their local community to potentially being of relevance to the broader world.

Knowledge work that matters pervades one's life (pervasive knowledge building). This principle encourages students to view all problems and questions, both "in and out of school, as occasions for building knowledge" (Scardamalia, 2002, p. 78). Thus, all students' questions and interests outside of school are validated and recognized as being worthy of study. This blurs the boundaries between school and other areas of students' lives, and encourages them to recognize science as being applicable and relevant to all aspects of their lives (Kozoll \& Osborne, 2004).

Knowledge work extends beyond the walls of the school to connect to the real world (symmetric knowledge advancement). "Expertise is distributed within and between communities. Symmetry in knowledge advancement results from knowledge exchange and from the fact that to give knowledge is to get knowledge" (Scardamalia, 2002 , p. 78). Considered in combination with the other two principles related to fostering engagement with the outside world, this principle suggests that a KBC should function in a transactional manner with the world outside of the classroom, with both benefiting from the relationship.

\section{Example I: Knowledge Building About Earth, Air, and Outer Space}

The following example illustrates the manner in which the KBC model focuses a community on creating collaborative knowledge. This example is of 20 grade $5 / 6$ students in a laboratory school setting and their efforts to build knowledge about earth, air, and outer space. This example is a recounting of a year of knowledge building while the lead author was a classroom teacher. Ahead of the start of the school year the grade 6 topics of Flight and Outer Space were identified as the potential focus of study for the incoming class of students. However, this choice was not revealed to the students and no attempt was made to prepare the classroom for the anticipated knowledge building. On the first day of school the students entered a room that was devoid of any evidence of a preconceived idea about what they were going to be studying that year. The first assignment was for the students to go home and return to class with "something that they didn't get about the world." Students were encouraged 
to bring in newspaper clippings, magazine articles, or just their own thoughts. A bulletin board was set up to display the perplexing topics and the group engaged in discussion that ensured contributions by all members of the group could be heard and responded to by all members of the class (see Crosstalk in Brown \& Campione, 1996). This cycle of bringing in topics and discussing them was repeated over a three-week period, with common themes being identified and some problems of understanding being settled through discussion and research. At the end of this period of time, the class had identified a set of knowledge problems that were to encompass and launch their substantive knowledge-building work. These topics were physically posted under what became known as the "curriculum umbrella" to signify that they had something in common and were problems that the community had agreed were worthy of study. Beyond the curriculum-based topics of Flight, Earth, Weather, and Outer Space the following expansive set of problems of understanding were identified and worked on during the school year (see Figure 1).

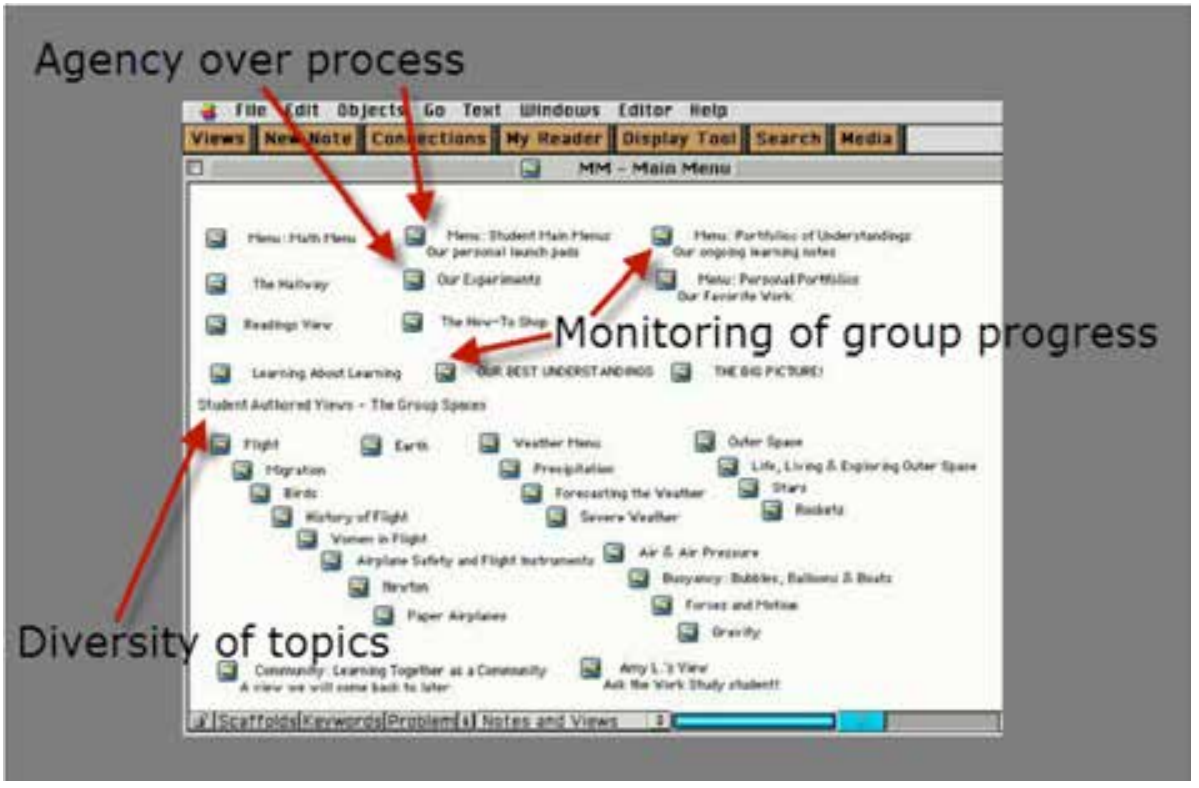

Fig. 1: Annotated screen capture of Main View of Knowledge Forum database displaying the full array of topics and work spaces available to the students. Group and individual portfolios were used to monitor developments in the knowledge work. Student-generated science experiments were entered in the "Our Experiments" view.

To support the work of this community several common design features were utilized, including the following. 
Reciprocal reading: Taking a critical stance on resources. An adapted form of Reciprocal Teaching (RT) (Brown \& Campione, 1996) was used to assist students in addressing resource material that was written above a grade $5 / 6$ level. This was necessary to provide students with reasonable access to the content of these resources, and more generally to the material that was associated with the problems they were addressing. Where RT stresses the use of roles to promote comprehension strategies, the approach that was taken in this classroom was more generally a group process focused on determining the resources' relevance and support for the research question.

Crosstalks/KB talks. A discussion format called Crosstalk (Brown \& Campione, 1996) or KB Talk used off of the computers to support the knowledge-building discourse. This design feature connects all members together in dialogue around a single knowledgebased concern. In the version of Crosstalk that developed in this classroom, there was a set of rules and processes that included: students sat in a circle along with the teacher; the teacher being treated as an equal member of the group and needing to raise his hand to speak; no one raising his or her hand to speak until the previous person had finished speaking; and the talk being based not on a topic but instead on a problem of understanding or knowledge advance furnished by one of the members of the class. The class held these sessions once a week for roughly 30 minutes, as there was always a problem of understanding or knowledge advance to share, discuss, and advance.

Portfolios as a means of embedding individual and group assessment. Portfolios were used within the database to monitor the growth of knowledge for each student as well as for the class as a whole. These "portfolios of understanding" (see Figure 1) were not static but evolved through the school year as a reflection of the students' knowledge work. Although the goal of a $\mathrm{KBC}$ is community knowledge development and embedded assessment, it was important to have individual students monitor and critique their own knowledge progress. As a result of writing their "portfolio notes," students would identify gaps and next steps that they viewed as critical to their forward progress and, in turn, the progress of the community.

Public sharing of knowledge work. A parents' night was held to celebrate and share the knowledge work that have been done by the class during the school year. This act of sharing constituted a limited form of action and outreach in the world outside of the classroom. The views in the KF database, along with other physical artifacts of their knowledge building (e.g., wind tunnel), were presented to the parents. This night was a culmination of their work; however, throughout the school year the parents had also been encouraged to come in before class to sit and have their child guide them through their child's portfolio notes and any relevant $\mathrm{KF}$ views. 
Social justice in example I. Students had agency over both the content and the processes by which knowledge was created in this knowledge-building community. Topics not initially considered by the teacher (e.g., Women in Flight; Buoyancy \& Bubbles) were brought in under the "curriculum umbrella" by the students, such that they were treated as important areas of knowledge development that would be of benefit to the community. Students accessed sophisticated resources (e.g., a university gravity text) and interacted directly with individuals in the outside world (e.g., e-mailing a professor) to gain information to support their knowledge-building efforts. The KBC that developed utilized several design features that assisted in bringing all students into the work, including the generative use of the KF environment, weekly Crosstalks, regular reading groups, and the use of reflective portfolios to assess the progress of individuals and the group. In terms of the main goals of science education for social justice, the level and nature of participation by members of this KBC made it possible for all students to become legitimate contributors to the social situation. This example illustrates the first goal of science education for social justice-ensuring that science education is accessible for all students. The next example follows a similar trajectory in terms of implementing the common design features, but more directly addresses the second goal of science education for social justice - facilitating student commitment to taking action to create a more socially just and environmentally sound world.

\section{KBC Example II: Knowledge Building International Project}

This KBC example involves a class of 18 grade 5/6 students at a private school in a Canadian city as they participated in the Knowledge Building International Project (KBIP). The KBIP was a network of schools engaged in building knowledge about climate change (Laferriére, 2008). Since all of the design features outlined in the first example were also used in this classroom, we will not outline these here. After a brief description of the project, we focus our discussion on the classroom processes related to science education for social justice.

As is generally the case with the study of climate change in schools (Svihla \& Linn, 2012), the causes of climate change were initially the central concern for this KBC (e.g., greenhouse effect with a focus on energy transformation). These questions were taken up through engaging in reading groups, and interacting on Knowledge Forum and in Crosstalk meetings. There was also a clear focus on the global consequences of climate change. These global effects were generally brought into the KBC discourse by the teacher through films (e.g., An Inconvenient Truth; Six Degrees) and also through books on the topic (e.g., This Is My Planet: The Kids' Guide to Global Warming). 
The consequences of climate change, such as deforestation and the severity of natural disasters, were topics of inquiry that were of significant concern to the students.

In this $\mathrm{KBC}$, connections to the outside world were clearly enhanced because of the focus on the socio-scientific issue of global warming/climate change. In addition, as the knowledge building progressed, various levels of environmental actions were engaged in by the students, including: 1) personal; 2) family; 3) community/societal (Sharkawy \& Reeve, forthcoming). Personal initiatives were identified as instances when students used their learning to effect change in their personal lives (e.g., changes in products they purchased; personal energy consumption; dietary changes). Family initiatives described how students used their learning to effect change in the lives of significant others in their family. Examples included: engaging parents in discussions on environmental issues (e.g., environmentally friendly cars to purchase for the family); encouraging family to reduce electrical consumption; and cutting down on consumption of products they considered unhealthy for the environment (e.g., bottled water; meat). Community/ societal initiatives were identified as socio-political actions, such as students writing to members of government to promote changes in an environmental policy/practice.

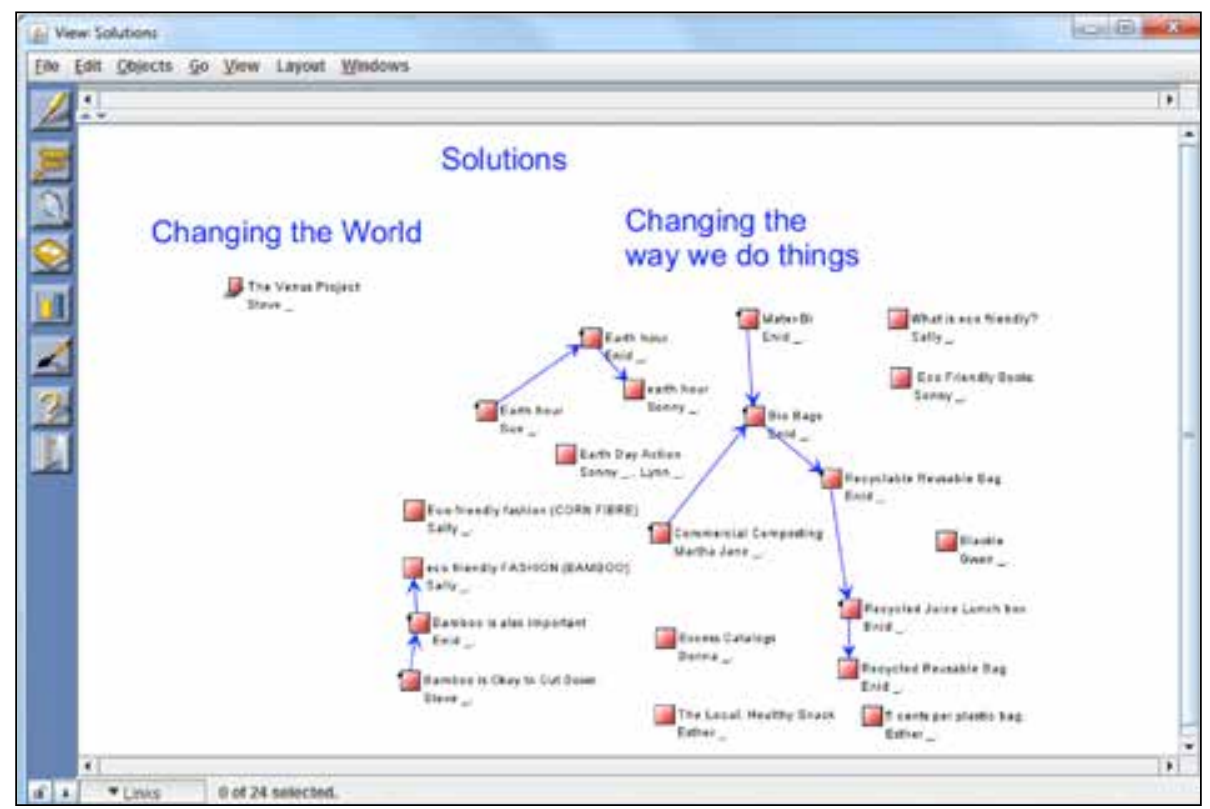

Fig. 2: Screen capture of the Solutions view in Knowledge Forum database for Example II. Screen capture taken at end of first term of the study. Student focus is on the changes/actions that can be taken by the group. 
Early in the process students were made aware that they were part of an international network and that their knowledge work would eventually be made available to the broader Knowledge Building International Project. A presentation was subsequently made via a videoconferencing system at the end of the knowledge building. Students also shared their knowledge advances with each other and presented their knowledge to other classes in their school (e.g., local community).

Social justice in example II. Overall, the activities undertaken by this KBC seem to have helped foster student engagement with the outside world as students developed knowledge that was not only of value to the local community, but also to the broader set of communities participating in the KBIP. Students were also engaged with the outside world through their interaction with an authentic problem, constructive uses of authoritative sources, the pervasiveness of the knowledge building in their lives, and their contact with other knowledge-building communities around the world. Above all this example demonstrates how students in a KBC can begin to commit to taking action to create a more socially just and environmentally sound world.

\section{Concluding Remarks}

The knowledge-building community model-its principles, unique technology, and classroom processes-provide valuable resources that support the goals of science education for social justice. It promotes the legitimate participation of all members of a community by building on students' cultural resources, interests, and concerns. The KBC model invites and promotes the inclusion of a diversity of voices, viewing this as essential to both knowledge growth and also the development of a democratic and socially just society. The KBC model also emphasizes a collaborative community, and progressive inclusive dialogue as the underlying contour of all interactions between its members. As a result, the KBC model provides an excellent foundation for making science education accessible for all students, among the many important goals of science education for social justice. What the KBC model does not explicitly and deliberately advocate is encouragement for students to take action on socio-political and environmental issues. However, despite the KBC model's lack of emphasis on this, teachers can choose to incorporate an action component into their teaching. Those that do so, as was the case in the second example, will be taking the KBC into a fuller rendering of what science education for social justice can begin to achieve in schools. 


\section{References}

Aikenhead, G. (2006). Science education for everyday life: Evidence-based practice. New York: Teachers College Press.

Banks, J. (1996). Multicultural education, transformative knowledge, and action: Historical and contemporary perspectives. New York: Teachers College Press.

Barton, A. (2003). Teaching science for social justice. New York: Teachers College Press.

Bencze, J. L., \& Alsop, S. (2009). Anti-capitalist/ Pro-communitarian Science \& Technology Education. Journal for Activist Science \& Technology Education, 1(1), 65-84.

Brown, A., \& Campione, J. (1996). Psychological theory and the design of innovative learning environments: On procedures, principles, and systems. In L. Schauble \& R. Glaser (Eds.), Innovations in learning: New environments for education (pp. 289-325). Mahwah, NJ: Lawrence Erlbaum Associates.

Caswell, B., \& Bielaczyc, K. (2001). Knowledge Forum $^{\oplus}$ : Altering the relationship between students and scientific knowledge. Education, Communication \& Information, 1(3), 281-305.

Cole, C.K. (2009). Something incredible wonderful happens: Frank Oppenheimer and the world he made up. Boston: Houghton Mifflin Harcourt.

Dewey, J. (1916). Democracy and education. New York: Free Press

Goldstein, J.S. (1992). A different sort of time: The life of Jerrod R. Zacharias. Cambridge, MA: MIT Press.

Hawkins, D. (1974). The informed vision. New York: Agathon Press, Inc.

Hein, G. (2012). Progressive museum practice: John Dewey and democracy. Walnut Creek: Left Coast Press.

Hmelo-Silver, C., \& Barrows, H. (2008). Facilitating collaborative knowledge building. Cognition and Instruction, 26, 48-94.

Hodson, D. (1998). Teaching and learning science: Towards a personalized approach. Buckingham: Open University Press.

Hodson, D. (2003). Time for action: Science education for an alternative future. International Journal of Science Education, 25(6), 645-670.
Kozoll, RH., \& Osborne, MD. (2004). Finding meaning in science: Lifeworlds, identity and self. Science Education, 88(2), 157-181.

Laferriére, T. (2008). Knowledge Building International Project 2008-2009 - Workshop. Institute for Knowledge Innovation and Technology Summer Institute. Toronto.

Moll, L. (1992). Bilingual classroom studies and community analysis: Some recent trends. Educational Researcher, 27(2), 20-24.

Nieto, S. (2010). The light in their eyes: Creating multicultural learning communities. New York: Teachers College Press.

Roth, WM., \&Barton, A. (2004). Rethinking Scientific Literacy. New York: RoutledgeFalmer.

Scardamalia, M. (2002). Collective cognitive responsibility for the advancement of knowledge. In B. Jones (Ed.), Liberal education in a knowledge society (pp. 67-98). Chicago: Open Court.

Scardamalia, M., \& Bereiter, C. (1996). Computer support for knowledge-building communities. In T. Koschmann (Ed.), CSCL: Theory and practice of an emerging paradigm (pp. 249-268). Mahwah, NJ: Lawrence Erlbaum Associates.

Scardamalia, M., \& Bereiter, C. (2003). Knowledge building. In J. W. Guthrie (Ed.), Encyclopedia of Education (2nd ed., pp. 1370-1373). New York: Macmillan.

Scardamalia, M., \& Bereiter, C. (2006). Knowledge building: Theory, pedagogy, and technology. In R. K. Sawyer (Ed.), Cambridge handbook of the learning sciences (pp. 97-118). New York: Cambridge University Press.

Sharkawy, A., \& Reeve, R. (forthcoming). A knowledge building approach to student agency and environmental actions: International Journal of Environmental Education.

Svihla, V., \& Linn, M. (2012). A design-based approach to fostering understanding of global climate change. International Journal of Science Education, 34(5), 651-676.

Tarchi, C., Chuy, M., Donoahue, Z., Stephenson, C., Messina, R., \& Scardamalia, M. (2013). Knowledge building and knowledge forum: Getting started with pedagogy and technology. LEARNing Landscapes, 6(2), 385-404. 


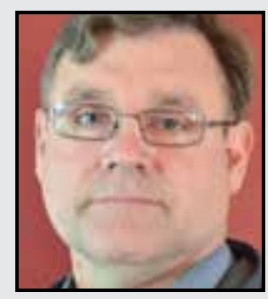

Richard Reeve is an Assistant professor of information and communication technology in teaching and learning at the Faculty of Education, Queen's University. He is formerly an elementary school teacher. Broadly speaking, Richard's research examines classroom-based uses of educational technology. In particular, his work has examined the development of technology-supported knowledge-building communities. In addition, he explores the moves teachers make as they design ways for technology to benefit students. Currently, Richard's research focuses on studying teachers as they work collaboratively to develop innovative approaches to teaching with technology, and the professional development contexts that provide support for these "designerly" endeavours.

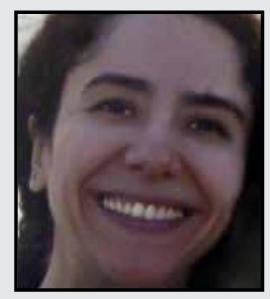

Azza Sharkawy is an Associate Professor of science education at the Faculty of Education, Queen's University. She is a former elementary school teacher. Her research interests include students' conceptions of science and scientists, equity issues in science education, and action research. 